\title{
The Value of sustainability
}

\author{
Andy Lewry ${ }^{1,}$, James Fisher ${ }^{1}$, and Matt Holden ${ }^{2}$ \\ ${ }^{1}$ BREEAM Existing Buildings Team, BRE Global, WD25 9XX, UK \\ ${ }^{2}$ BREEAM - Operations, Management \& Strategic R\&D, BRE Global, Watford, WD25 9XX, UK
}

\begin{abstract}
As the market place becomes increasingly competitive and there is a need to be able to differentiate oneself as a high performer. Andrew Vaughan the CEO of Redevco stated 'Greening our portfolio over the next two years is not only environmentally the right thing to do, it also makes sound business sense.' Buildings built and/or managed to sustainability standards, such as BREEAM have been shown to minimise risk and generate maximum profit via:
\end{abstract}

- High and continuous rental income;

- Low operating \& maintenance cost;

- Low depreciation.

UK valuers do not think we are paying a premium for green buildings but having to give a discount because the building is not performing well. This gives a convincing business case for new build where the certification process leads to a high-performance building.

However, what about the existing building stock?

Is the operational environmental performance of an asset reflected by its investment performance?

This paper describes a new research project which aims to test the Hypothesis -

Better operational performance in-use leads to improved investment performance of commercial offices. Improved operational performance goes "hand-in-hand" with environmental performance; where the performance can be illustrated by certification and labelling schemes.

\section{INTRODUCTION}

The management of real estate investments is aimed at maximising property value and return on investment [1] via:

- Effective risk management;

- Efficient property management;

- Identification and implementation of valuable improvements.

In the current highly competitive market place the "Challenges for Real Estate Clients" are:

- Increasing profit;

- Maintaining competitive edge;

- Driving asset yield;

- Minimising voids;

- 'Being the best on the street';

- High productivity workspaces.

Green buildings have always been considered high performance because the certification schemes are based on ratings which drive design of the asset towards the high end. The benefits can be seen in Figure 1; which is further endorsed by the valuers who are changing their position from "paying a premier for green buildings" to "having to give a discount because the building is not performing well". However, to change the valuers professional guidance from a recommendation to a quantifiable metric, an evidence base is required.

High-performing buildings provide a solution to discounting in that they have been shown to generate maximum profit via:

- Asset protection;

- High and continuous rental income;

- Low operating \& maintenance cost;

- Low depreciation.

For example, studies on certified buildings have shown the increase in rentable value is to be a maximum of $25 \%$ but an average of between $5-10 \%$ is more realistic (see Figure 2).

\footnotetext{
* Corresponding author: LewryA@bre.co.uk
} 


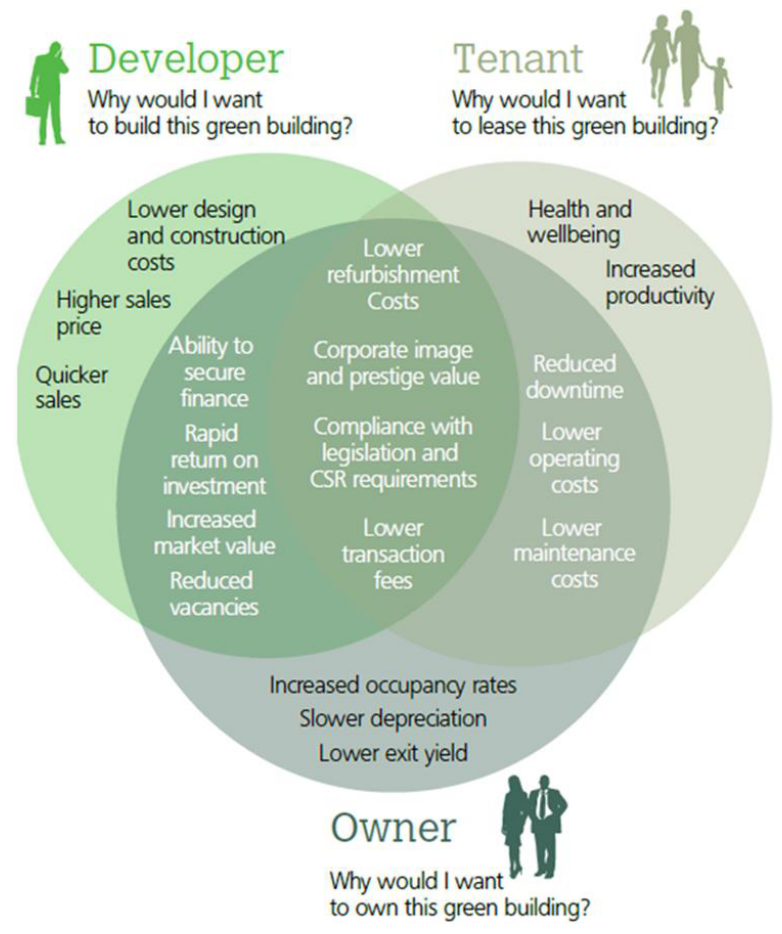

Fig. 1. The Stakeholders in Real estate asset management [2]

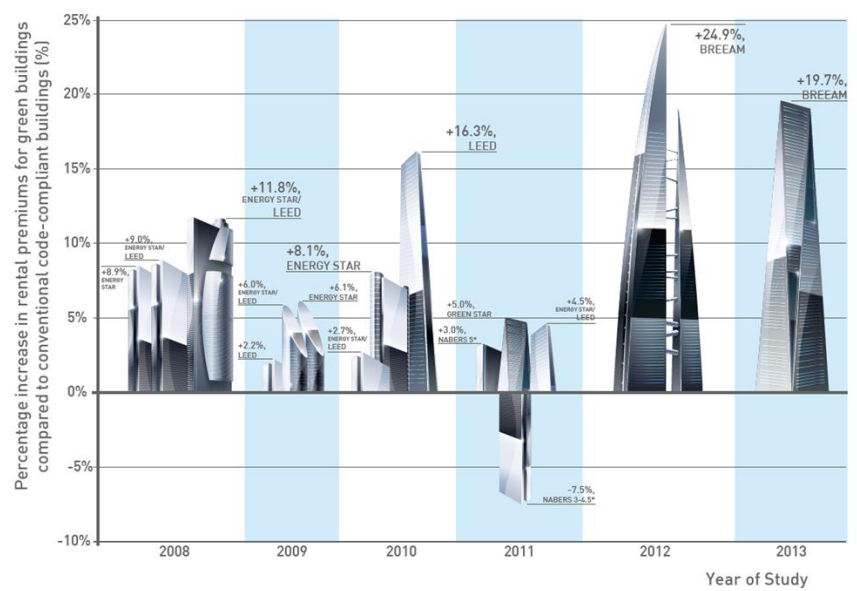

Fig. 2. Studies on the rentable value for green buildings [3]

There are also several case studies, for example the BREEAM certified Manfield House shown in Figure 3. The benefits were quoted as [4]:

"From an investment perspective, it also bolstered marketability and reduced obsolescence risk. On launch of Manfield house (see figure 3), we were able to advertise the letting at $£ 65$ per square foot - an improvement of some $20 \%$ on our expectations when we first undertook the project.'

Dr Steve Waygood, Chief Responsible Investment Officer Aviva Responsible investment update, Spring/Summer 2015.

However, this is not an unbiased sample as all are new build; built to a high standard to pass certification and achieve high ratings; and then branded as such - of course you would expect high asset and rental values.

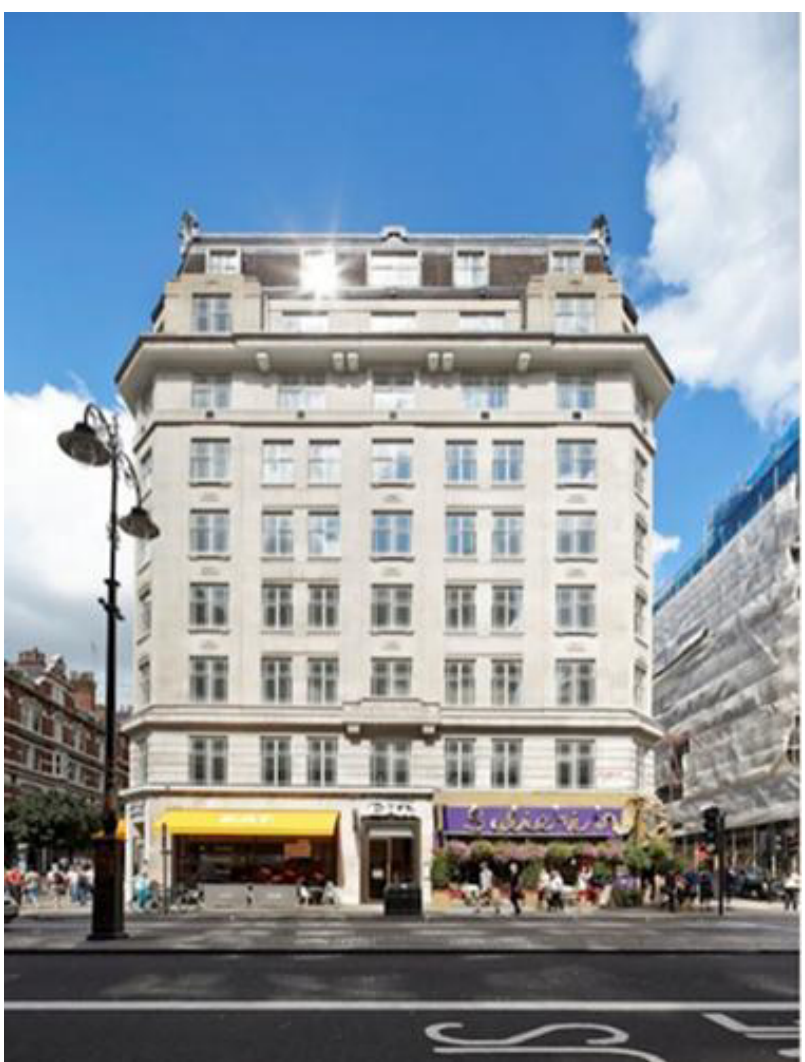

Fig. 3. Manfield House, Southampton Street, London [4]

Therefore, the benefits of high performance buildings can be realised by the use of third party certification.

As a process it facilitates:

- Client engagement;

- Communication within project team and between developers and their clients;

- Common language: standards, methods and data flows.

With 3rd party certification it realises the following benefits:

- Assurance for clients, investors \& other stakeholders;

- Comparability across building types and countries;

- Based on sound science and standards;

- One step ahead of legislation and industry best practices.

\section{PREVIOUS RESEARCH}

There is a well-established body of empirical research investigating the relationship between voluntary and mandatory energy/environmental labels and prices in the commercial and residential real estate markets. Most of these studies in the commercial office sector have been in the US. Overall there are around 50-60 local and national level studies in the commercial and residential sectors that have tried to estimate price effects in mainly developed, wealthy markets such as UK, Australia, 
Singapore, Sweden, Germany, Switzerland, Netherlands, etc.

A relatively small number of the studies have incorporated indicators of environmental performance in-use. In the US, some studies have identified an "operational expense puzzle" for Energy Star rated buildings [5]. They found that, compared to buildings without eco-labels, operational expenses of eco-labelled buildings are unexpectedly higher. There is also evidence of an energy performance gap in both residential and commercial properties between asset ratings based on hypothetical performance and actual energy consumption in use.

In Europe [1] and in particular the UK [6, 7] there has been research done to investigate the relationship between asset and operational energy ratings - the gap found in these UK studies is between 200 and $450 \%$. BRE has been at the forefront of this research $[8,9]$ and is currently carrying out a research project on several UK office buildings [10].

The initial findings from this "Mind the gap" study [11] were:

- The performance gap was confirmed as real and in the range of 209 to $491 \%$;

- The values observed were similar to that observed by previous studies which were between 200 and $450 \%$;

- There was no relationship between the perceived operational status and that observed;

Another study [12] found from 62 case study buildings, the average discrepancy between predicted and measured energy use was $+34 \%$. In their literature review, the most important underlying causes identified were building modelling specification uncertainty, occupier behaviour and poor practice in operation. However, these were case studies and not typical; in addition, management issues were not considered; therefore, the real gap in the market place was probably underestimated.

The effect on the asset and its value is just as dramatic with:

- Deterioration of value;

- Service life of plant reduced;

- Fabric lifetime reduced;

- Costly remedial works to maintain value;

- In 'void' periods where there is likely to be still further deterioration through lack of use;

- Loss of reputation.

\subsection{BRE research}

BRE last ran a study of this nature in 2012 [13], in partnership with Nils Kok and Maastricht University. The report showed a positive correlation between both rental and sales prices of BREEAM rated buildings versus non-BREEAM rated ratings. Whilst this was taken as a positive, it was noted in the final output from the project that whilst the numbers looked impressive, the reason could have been related to the lack of a building and location quality control.

Results from this study were similar to those obtained in the American version of the same report before location and building quality controls were implemented, a much lower but altogether more believable number resulted once these controls were implemented in the American study [14].

Recent breakfast briefings held by BRE on the Performance Gap collected the workshop observations, which will be published in a briefing paper [15]; the industry comments included "there is a lack of evidence for the connection between building performance and asset value", although some noted that there are moves to make this connection more apparent.

\section{PROPOSED RESEARCH PROJECT}

The aim of the new BRE lead project is to investigate the relationship between environmental performance in-use and investment performance of commercial offices.

As previously mentioned the last BRE led report in this area was published in 2012 [13] and its focus was heavily on new build offices in London as such it is necessary to update this work and expand on the scope to take account of other locations outside of the United Kingdom, other building types and different lifecycle stages. It is planned that the piece of work that will be carried out will be the first in a series of annual reports building on the existing suite of third party research highlighting the benefits to various stakeholders outlined later.

The project will build on the existing available literature adding to the assertion that obtaining a BREEAM rating does drive value in terms of rental price, sales price, yield, void times and lower overall investor risk. The benefits also manifest in terms of lower utility bills and, anecdotally, through increased occupant health \& wellbeing and productivity. This study would not look to focus on these latter areas, concentrating instead on the benefits related to investors, building managers, fund managers, building owners and occupiers.

Specifically, we wish to test the following hypothesis:

"Better operational performance in-use leads to improved investment performance of commercial offices. Improved operational performance goes "hand-inhand" with environmental performance; where the performance can be illustrated by certification and labelling schemes."

Figure 4 outlines potential transmission mechanisms between operational environmental performance and investment performance. 
To our knowledge, no studies have examined the relationship between the buildings (certified or uncertified) according to their environmental performance in-use and their performance as investments.

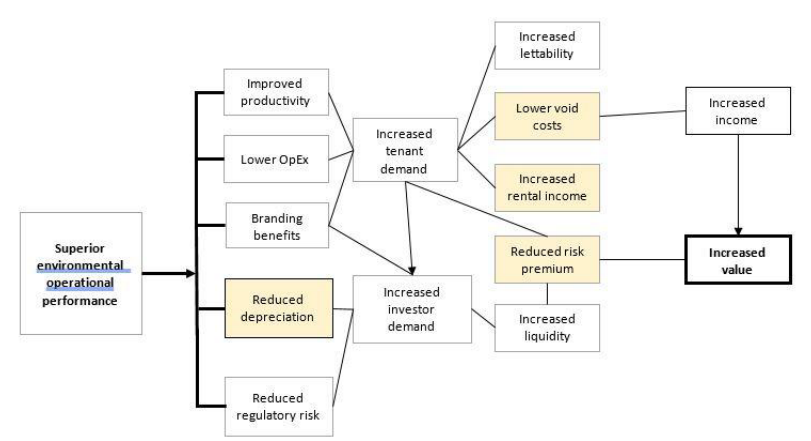

Fig. 4. Potential transmission mechanisms between operational environmental performance and investment performance.

\subsection{Proposed research method}

Specifically, the proposed research aims to investigate the relationship between operational and environmental performance in-use and the investment performance of existing commercial offices. Operational and Environmental performance would be measured using the BREEAM-In-Use (BIU) certification scheme and investment performance would be measured using rents, capital prices and returns (total, capital and income).

The body of research on the determinants of financial performance of eco-labelled buildings discussed above provides a recognised basis for specifying econometric procedures that can robustly identify the effect of environmental performance in-use on investment performance whilst controlling for additional, perhaps much more important, determinants of investment performance such as location, market conditions, tenant quality, etc. The study will therefore require data on a wide range of variables that could also have affected the investment performance of the asset.

Previous studies suggest that data on the following would be required.

1. Operation: lease terms, vacancy rates, time-onmarket, service charges, operating expenses.

2. Operational and Environmental performance: the scope of the BREEAM-in-Use model seems comprehensive in this respect.

3. Building attributes: specification, size, location, age, services and facilities, design, tenant quality, etc.

4. Attributes of urban economy: a range of demand and supply indicators, economic growth, vacancy rates, etc. at sector, market and national levels.

\subsubsection{Data}

The key challenge for a research project of this type is assembling sufficient data to enable a rigorous investigation to be undertaken and robust conclusions to be drawn. Real estate data is notoriously difficult to obtain, and the difficulty is exacerbated here because operational and environmental performance data; and investment performance data are likely to be held by different organisations within the real estate industry. This means that the two sets of data will need to be joined at the building level and perhaps the sub-building level for multi-let assets. The best approach would seem to be to approach investors who would then provide the requested information.

Not surprisingly, in general private sector organisations that hold data are commercially motivated. The samples that they have gathered may be client driven and, consequently, can be partial proprietary, private and product-related. This leads to the discussion of how to generate additional data points and homogenise datasets to ensure comparability. We consider this would be best done by putting all buildings into the same version of $\mathrm{BIU}$

Consequently, key data risks are:

- Inadequate sample size: do sufficient observations exist to draw statistically inferences?

- Data sets are not intrinsically linked requiring the both sets to be statistically representative and significant.

- Omitted variables: is it possible to compile data on a sufficient number of potential determinants of investment performance?

- Data sets to be representative of that market place and not biased because of the fact high performance buildings need good data to be just that.

We consider the generation of alternate, primary, data as part of study could help solve this problem. A potential tactic here is to target financial data first and generate the performance and environmental data for those assets.

\section{SUMMARY}

A critical early task to enable this research is the compilation of data sets on the environmental and investment performance of a sample of existing office buildings. The sample needs to be of sufficient size and the data needs to be of sufficient depth to allow an econometric analysis of determinants of investment performance. The methodology leads to the need to obtain financial data first and then for those assets generate the performance and environmental data.

As a consequence, BRE are actively seeking partners in the Real Estate sector to support this project. 


\section{References}

1. International Energy Agency, Mind the Gap: Quantifying Principal-Agent Problems in Energy Efficiency, , (2007), available at https://www.iea.org/publications/freepublicatio ns/publication/mind the gap.pdf. (accessed 17th Dec. 2018).

2. DLA Piper report, 'Towards a greener future', (2014), https://www.dlapiper.com/ /media/Files/Insight s/Publications/2014/03/towardsagreenerfuture.p df. . (accessed 17th Dec. 2018).

3. World Green Building Council report, 'Business case for green building', (2013),

http://www.ukgbc.org/sites/default/files/World \%20GBC\%20Business $\% 20$ Case $\% 20$ for $\% 20$ Gre en\%20Buildings.pdf. (accessed 17th Dec. 2018).

4. BREEAM case studies, https://www.breeam.com/case-studies/. (accessed 17th Dec. 2018).

5. N. Szumilo, N. and F. Fuerst, The operating expense puzzle of US green office buildings. Journal of Sustainable Real Estate, (2014), 5(1), pp.86-110.

6. UK Green Building Council 'Delivering Building Performance", Task Group Report', (2016), available at http://www.ukgbc.org/sites/default/files/UKGBC\%20Task\%20Group\%20Report\%20Delive ring\%20Building\%20Performance.pdf (accessed 3rd July 2018).

7. Innovate UK 'Building Performance Evaluation Programme: Getting the best from buildings findings from non-domestic projects', (2016), available at https://www.gov.uk/government/publications/lo w-carbonbuildings- best-practices-and-what-toavoid (accessed 3rd July 2018).

8. A. J. Lewry, J. Ortiz, J., A. Nabil, N. Schofield, R. Vaid, S. Hussain and P. Davidson, 'Bridging the gap between operational and asset ratings - the UK experience and the green deal tool', (2013), BRE briefing paper KN5477, available at

https://www.bre.co.uk/filelibrary/pdf/other pdfs /KN5477 Energy_Paper_v1.pdf (accessed 3rd July 2018).

9. A. J. Lewry, 'Bridging the performance gap: Understanding predicted and actual energy use of buildings', BRE IP 1/15, (2015), IHS press, available at http://www.bre.co.uk/energyguidance (accessed 3rd July 2018).

10. A. J. Lewry and L. Hamilton, 'Mind the gap": The difference, in performance, between design and the building 'in-use', Journal of Building
Survey, Appraisal \& Valuation, (2017), Vol. 6, No. 1, pp 60-66.

11. A. Lewry, L. Hamilton, M. Hadi, J. Bennett, and P. Richards. Designing the "mind the gap" project - investigating the difference, in performance, between design and the building "in-use", Proceedings of RCEPB2018 (10th Int. Conf. on Energy Performance of Buildings), (2018), Congress hall, TUCEB, Bucharest, Romania.

12. C. van Dronkelaar, M. Dowson, E. Burman, C. Spataru, and D. Mumovic, A review of the energy performance gap and its underlying causes in non-domestic buildings, (2016) Frontiers in Mechanical Engineering, 1, 17.

13. A. Chegut, P. Eichholtz, and N. Kok, Supply, Demand and the Value of Green Buildings, (2012), RICS research report, RICS, London, UK.

14. A. Devine, E. Steiner, and E. Yönder, Decomposing the Value Effects of Sustainable Investment: International Evidence, (2017), ERES eres2017_346, European Real Estate Society (ERES).

15. A. J. Lewry, and S. Guy, The performance gap in buildings - what real estate investors, owners and asset managers need to know, (2018), BRE Briefing Paper. BRE, UK. 